\title{
CONCEPTOS FILOSÓFICOS QUE INFLUYERON EN LAS PARADOJAS DE CONJUNTOS DESCUBIERTAS POR BERTRAND RUSSELL
}

\author{
Felipe Maya \\ Universidad de Málaga
}

\begin{abstract}
Resumen. En este artículo examino algunos presupuestos filosóficos de Bertrand Russell que subyacen a su descubrimiento de las paradojas en la teoría de conjuntos de Cantor: los juicios a priori y sintéticos de Kant, el logicismo de Leibniz, la cosmovisión hegeliana, el argumento ontológico de san Anselmo.

Palabras clave: Russell; Cantor, Kant, Hegel, Leibniz, san Anselmo, juicios $a$ priori, juicios sintéticos, logicismo, infinito potencial, infinito actual.

PHILOSOPHICAL CONCEPTS THAT INFLUENCED THE PARADOXES OF SETS DISCOVERED BY BERTRAND RUSSELL
\end{abstract}

Abstract: In this paper I examine some of Bertrand Russell's philosophical presuppositions underlying his discovery of paradoxes in Cantor's set theory: Kant's a priori and synthetic judgments, Leibniz's logicism, the Hegelian worldview, St. Anselm's ontological argument.

Keywords: Russell; Cantor, Kant, Hegel, Leibniz, Saint Anselm, a priori judgments, synthetic judgments, logicism, infinite potential, infinite actual.

Recibido: 4 de mayo de 2021

Aceptado: 30 de junio de 2021

DOI 10.24310/NATyLIB.2021.vi15.12491

El trabajo que presento a continuación tiene la finalidad de presentar las influencias filosóficas que llevaron a Bertrand Russell a descubrir las paradojas de la teoría de conjuntos. Dicho trabajo puede ser encorsetado en el marco de la divulgación científica, puesto que no contiene ideas nuevas ni originales en cuanto a la ciencia. Es, más bien, una colaboración expositiva para dar un vehículo universal a la tesis presentada por el Dr. Alejandro R. Garciadiego Dantan en el libro Bertrand Russell y los orígenes de las «paradojas» de la 
teoría de conjuntos. El libro anterior no es el único medio por el cual Garciadiego presenta una reconstrucción histórica fidedigna del descubrimiento de las paradojas de los conjuntos; pese a ello, es una buena base para quien desee informarse mejor del desenlace de este acontecimiento.

Existe en la literatura, incluso especializada, un binomio de no fácil solución a la hora de realizar historia de las matemáticas. Cuando un historiador, sin conocimientos matemáticos adecuados, pretende hacer historia de las matemáticas, suele desarrollar trabajos con un cuadro correcto en las ciencias sociales y, pese a ello, estar bastante errado en aspectos matemáticos que se escapan de su alcance. En la dirección opuesta también abundan graves omisiones: un matemático que sin bases pertinentes en el método empleado por historiadores, busca hacer historia de las matemáticas, en muchos casos realiza un material histórico deficiente plagado de excelentes matemáticas. El trabajo de Garciadiego es un maravilloso ejemplo de un desarrollo histórico y matemático preciso, novedoso y esclarecedor y, sobre todo, muy delicado en el cuidado de los detalles pertinentes a ambas disciplinas. Garciadiego exhibe una reconstrucción de cómo fueron encontradas las tres paradojas de la teoría de conjuntos a inicios del siglo XX. Esta versión contradice lo que él llama la «interpretación estándar» de la historia que es, a saber, aquel relato en el que nos han presentado los datos de este acontecimiento y que, pese a tener diferencias dependiendo de los historiadores, frecuentemente coinciden en lo esencial: Burali-Forti descubrió su paradoja en 1897; Cantor comunicó por carta a Dedekind una proposición similar a la de Burali-Forti en 1899 y, por último, Bertrand Russell descubrió su paradoja en 1901 y notificó a Frege de su hallazgo, también por carta, en 1902. La síntesis anterior contiene aquello que, en general, se da por sentado cuando se habla de la invención (entiéndase la palabra en su acepción de hallazgo y no de creación, in-venire en latín) de las paradojas de conjuntos. Esta versión oficial, no obstante, deja muchas incógnitas sobre la marcha, que no embonan satisfactoriamente con la forma en que se sucedieron los acontecimientos hasta nuestros días. Cuando se rastrean, por ejemplo, la correspondencia, cartas o trabajos de Burali-Forti, no se encuentra en ellos rastro de que este matemático italiano, discípulo de Peano, estuviera consciente de haber sido quien hallara lo que ahora denominamos su paradoja. Otro tanto sucede con Cantor cuando se hace una lectura juiciosa de 
sus escritos. Muchas veces la óptica de interpretación se ve modificada por el paradigma con el que se estudia, aunque el propósito del autor hubiera sido otro al escribir. Garciadiego ofrece una versión de la historia muy distinta, en la cual demuestra por qué las tres paradojas fueron, más bien, descubiertas por Bertrand Russell y no así, por los otros dos matemáticos. Esta reconstrucción (por mucho más plausible que la estándar) encuentra su justificación en innumerables cartas, periódicos, revistas y ensayos del tiempo en que las contradicciones fueron descubiertas. Los conocimientos históricos y matemáticos de Garciadiego le permiten hacer una mejor reconstrucción sobre los hechos del pasado y dar soluciones verídicas a cuestiones que, hasta entonces, estaban inconclusas o poco fundamentadas.

Tanto por la curiosidad que me generó el tema, como por la novedad de la versión histórica presentada por Garciadiego, he decidido realizar este trabajo en colaboración con él para, en la medida de mis posibilidades, ayudar a extender su exégesis del hecho histórico que, sin ser precisamente inédito, no ha permeado aún en el sentir de los historiadores y de los matemáticos con la velocidad deseada. Con este trabajo explico las influencias filosóficas que influyeron fuertemente en Bertrand Russell y que permitieron después que fuera él quien encontrara las paradojas. Si alguno desea un conocimiento más profundo, recomiendo ampliamente basarse en la bibliografía que presento al final del proyecto, la cual me sirvió de plataforma para escribir sobre este gran filósofo y matemático.

Bertrand Russell es, en primer lugar, un filósofo. No me refiero exclusivamente a la carrera universitaria por la que optó — que también-, pues a pesar de haber empezado matemáticas se cambió a filosofía y fue esta carrera la que culminó en Cambridge. Me refiero al llamarlo filósofo, a que lo es en el sentido amplio de la palabra. La filosofía, siempre tan ligada a la búsqueda de la verdad, no es una actividad exclusiva para aquellos que pueden gozar de un tiempo de ocio luego de haber subsanado las necesidades más elementales. Esto, sin ser forzosamente falso, no es uno de los parámetros indisolubles a esta ciencia; un ejemplo de ello lo encontramos en Albert Camus, quien tuvo un origen sencillísimo y una manutención no ajena a las dificultades. El desarrollo filosófico se acerca mucho más a un asunto de supervivencia: cuando un hombre se planta frente a cuestiones relativas al sentido de su vida y obtiene 
respuesta, el paso lógico siguiente es que su existencia adopte rumbo dependiendo de las conclusiones obtenidas. Responder a preguntas existenciales tales como ¿por qué se da la vida?, ¿para qué vivimos? o, aún más personal, ¿cuál es el sentido de $m i$ vida? marca gran diferencia en la postura que se toma en el día a día.

En Russell, desde temprana edad, este ser filósofo afloraba con ímpetu en su carácter y tan es una cuestión de supervivencia como decía antes, que a los once años ya había decidido suicidarse porque no encontraba gran sentido a su vida y esto, por una razón cabal, a saber: que no tenía certeza de qué cosas eran verdaderas y cuáles no. Sus dudas carecían de importancia para los adultos con quienes convivía y el marcado fideísmo de su abuela le ofuscaba la mente, a pesar de sus pocos años. Esto lo llevó a un prematuro desencanto de la existencia. Sin embargo, conoció la geometría de Euclides, cuestión que dio luz, una luz tenue e incipiente, a sus preguntas sobre la vida. Le pareció que dicha geometría mostraba un camino factible de saber si algo era verdadero o no. Es decir, descubrió que el mundo podía ser descifrable para la razón. Si comparamos esto con una de las definiciones reales de la filosofía (ciencia de todas las cosas por sus últimas causas y principios, a través de la luz natural de la razón), notaremos el gran símil de la búsqueda de Bertrand y la razón de ser del filósofo. Bertrand Russell fue, desde pequeño, un filósofo estrictamente hablando. Su vida, a partir de ahí, estuvo marcada por una búsqueda de la certeza que parecía no agotar sus fuerzas ni su sed intelectual. La filosofía personal u obtenida de otros, sería una guía en su obrar y en su pensar durante todos los años de vida que, por cierto, fueron casi cien. En cuanto a las conclusiones filosóficas resultado del exclusivo razonar de Russell, daremos su espacio más adelante. Ahora me permitiré mencionar pensadores que influyeron directa e indirectamente en él con más potencia. Para explicar a dichos autores me fío del gran bagaje cultural del poeta y filósofo Ramón Xirau, alumno y profesor de la UNAM, quien falleció hace unos años y dejó un profundo pozo de sabiduría en las aulas.

\section{Immanuel Kant}


Nació en Königsberg en 1724. A pesar de su aspecto lánguido y enclenque, murió de 79 años. Era un hombre religiosamente disciplinado a causa de su conocimiento propio. Dado su talante, más bien débil, suponía que debía suplir con cuidados su mala naturaleza: se vigilaba de un modo metódico la salud para intentar sustituir con precauciones lo que no le fue otorgado de nacimiento y, curiosamente, salió vencedor. Sin embargo, renunció a viajar, a contraer matrimonio y a exponerse a aventuras, con tal de conservarse inmune a las enfermedades. A pesar de no haber dado tres pasos más allá de su pueblo natal, Kant, era un hombre muy consciente de su tiempo y estaba al tanto de lo que sucedía en el mundo. Durante sus años de vida acontecieron dos hechos históricos relevantes: la Revolución Francesa y la Independencia de Estados Unidos, mismos que siguió con gran atención. Fue un personaje notablemente secular, a pesar de pasar su vida encerrado en el lugar natal. Su filosofía, en cambio, fue del todo innovadora. Lo poco que arriesgaba en lo físico, lo superaba con sus lances intelectuales. Sus más grandes aportaciones están condensadas en tres grandes libros: Crítica a la razón pura, Crítica a la razón práctica y, por último, Crítica del Juicio. No son los únicos libros que escribió, pero son ellos los que conglomeran lo más original de su pensamiento. Los textos previos muestran la gran influencia que tuvo de Leibniz y los posteriores son, a lo más, ya explicaciones, ya profundizaciones del pensamiento propio asentado en sus tres grandes obras.

Si la filosofía de Kant fuera un sistema planetario, comparación que él mismo se dignó hacer, el sol sería el conocimiento humano y su crítica. Es importante resaltar que para Kant la palabra 'crítica' no tiene precisamente el significado de oposición desfavorable sino, más bien, de estudio profundo e importante. Kant arrasó con la polarización que existía sobre el origen de las ideas. Los racionalistas, hasta ese momento, argüían que las ideas eran innatas; los empiristas argumentaban que las ideas se adquirían con la experiencia. Kant deja de lado el debate reinante y se preocupa del conocimiento mismo, partiendo de la base (como su axioma) de que es innegable que el hombre es un ser que conoce. Se propone así dilucidar los límites del entender. Es aquí, sobre todo, donde Kant marca un parteaguas no solo en filosofía, sino en la ciencia misma; pues en la ciencia esos límites están delineados por lo válido y lo posible. Kant rastrea al detalle las causas por las cuales en las ciencias sí 
es asequible un conocimiento con las características antedichas: válido, posible.

Posteriormente, Kant deduce que el pensamiento se da a través de juicios, pero dichos juicios no siempre se presentan bajo idéntico ropaje. Distingue pues, entre ellos, cuatro tipos: analíticos, sintéticos, a priori, a posteriori. Las verdades matemáticas son un excelente ejemplo de los juicios a priori, pues estas verdades, aunque puedan haber sido aprendidas por la experiencia, no dependen de esa experiencia misma. El hecho, por ejemplo, de saber que $1 \neq$ 0 , no depende de la experiencia personal aunque el interesado lo haya aprendido, o hecho consciente, en un día específico de su vida. Posiblemente el sujeto lo aprendió por experiencia, pero la verdad de este juicio supera, por mucho, cómo fue aprendido. Este juicio a priori tiene en sí mismo un valor inconmensurable. Los juicios a priori, dado lo dicho anteriormente, son para Kant (y aquí radica su valor) universales y necesarios. Universal porque no sucede que para algún ser racional dicho juicio no sea verdadero; necesario, porque para toda conciencia es igual. La ciencia misma está constituida con juicios a priori. Los juicios sintéticos, por otro lado, son aquellos que aportan algo nuevo dado que el sujeto del juicio no está contenido en el predicado. No deseo hacer aquí una explicación extensa de Kant y, por lo mismo, omitiré la glosa de los otros juicios dado que no interesan al propósito del escrito sobre Russell; a lo que deseo llegar, una vez que se han comprendido los dos tipos de juicios mencionados, es al problema que planteó para las ciencias este filósofo. La tarea de Kant, puesto que la ciencia da juicios sintéticos (de lo contrario no descubriría nada nuevo), es rastrear si esos juicios son, efectivamente, a priori. Es decir, universales y verdaderos. Esto, básicamente, es la Crítica a la razón pura y me parece suficiente para que el lector comprenda por qué Kant influyó de un modo tajante, no solo en los pensadores de su época sino hasta en el modo en que ahora mismo concebimos la ciencia.

Considero pertinente resaltar que Kant da un lugar importante a los juicios matemáticos de los cuales habla largo y tendido, bajo su concepto de 'estética trascendental'. Actualmente al hablar de estética posiblemente el pensamiento se dirija hacia lo bello y lo artístico. Sin embargo; el significado original de esta palabra se refería a lo sensible. Para Kant la estética trascendental hace referencia al modo sensible en que aprendemos los conocimientos a priori y 
para ello, argumenta que hay en especial dos intuiciones a priori que tienen mucha fuerza en el ser humano: el tiempo y el espacio. Me gustaría pedir al lector que no pierda de vista que Kant trata de determinar cómo es que conocemos. Sus conceptos de tiempo y espacio no son pues, en este contexto, los entes reales, sino el modo en que el ser humano percibe el tiempo y el espacio. Para Kant el tiempo y el espacio, en el contexto al que me refería antes, son intuiciones a priori, es decir, son capacidades del ser humano que le permiten entender estos conceptos. Este filósofo hace una demostración de que tanto el tiempo y el espacio son intuiciones a priori (demostración que no veo pertinente describir aquí) y, una vez desarrollada su prueba, argumenta que, dado que ambas son intuiciones a priori, entonces nuestra sensibilidad posee fundamentos universales y necesarios. Una vez hecho esto, se sigue que las ciencias que estudian el tiempo y/o el espacio poseen bases universales y necesarias y, por lo tanto, y nótese la fuerza de la conclusión, sus razonamientos están fundamentados en principios verdaderos. Lo anterior, a mi gusto, es uno de los mejores piropos que existen de las ciencias exactas.

Deseo enfocar la atención del lector en este último punto puesto que la geometría es una ciencia que presupone el espacio. Recordemos que Russell tuvo el deseo durante gran parte de su vida de demostrar la veracidad de los axiomas geométricos; fue ese el detonante de su curiosidad y, de hecho, fue la geometría de Euclides la que le acercó al mundo de la certeza de un modo que desconocía anteriormente. Será muy marcada la influencia de Kant en Bertrand Russell durante gran parte de su vida puesto que, en realidad, ambos estaban en la misma empresa filosófica: fundamentar la veracidad de las matemáticas. No solo ello, Russell consideró en muchos momentos de su vida (no en todos) que la matemática contenía verdades a priori. Creía él, Bertrand, que era una disciplina verdadera a pesar de que él no había conseguido demostrar los primeros principios de la geometría, pero, eso deseaba, lo haría en algún momento de su vida o cuanto menos, lo intentaría. No toda su vida pensó del mismo modo; no obstante, este aspecto abarcó, en conjunto, gran parte de su juventud y edad adulta. Pese a ello, hubo algún momento en que llegó a concebir a todas las ciencias, las matemáticas también por supuesto, como inherentemente erróneas. Esto, sin embargo, pertenece a un periodo de su vida 
en que su pensamiento estuvo mayormente influido por Hegel, incluso sin haber leído a este filósofo directamente. De hecho, la magia de los encantos que Hegel emanó en Bertrand llegó a su fin cuando Russell, por sugerencia de un profesor y amigo, leyó de primera mano a Hegel y no solo a sus comentaristas y seguidores. El desencanto que le generó fue tan fuerte que Bertrand abandonó de golpe muchas de las ideas más firmes que conservaba; otras tantas, en cambio, también de influencia hegeliana, permanecieron por un tiempo más arraigadas en su mente.

\section{Hegel}

El apartado anterior sirvió de preámbulo para indicar la influencia (indirecta) de Hegel en la vida de Bertrand Russell. Por ello explicaré, grosso modo, la importancia de este filósofo en la historia del pensamiento. Dicha influencia fue tal que por los tiempos en que Bertrand cursó sus estudios universitarios, la mayor cantidad de pensadores, quisieran o no, eran de un marcado corte hegeliano.

Este filósofo alemán, nacido en 1770, vio la luz en plena efervescencia del romanticismo. Pese a ello, su filosofía es más bien de corte racionalista y no podríamos juzgarla, de ningún modo, como un pensamiento sentimental si entendemos en ese sentido la palabra romanticismo. Por el contrario, si romanticismo lo entendemos en el sentido de cambio o de encontrar soluciones, como lo definiría Jacques Barzum, entonces la filosofía hegeliana sí encaja bien como romántica. El hincapié es para evitar confusiones en el marco histórico de dicha filosofía. Hegel, dicho rústicamente, pretende dar su lugar al cambio y al movimiento y ponerlos como escalafón de nuestra razón de ser. Es decir, pretende encontrar la suma de todas las manifestaciones anteriores del espíritu y poner el movimiento como parte de la esencia de nuestro mundo. Esta es la síntesis hegeliana y para ella emplea lo que conocemos como el método dialéctico. Este método pretende esclarecer que la verdad no se da de un modo unívoco ni de la identidad de las cosas a la realidad, sino más bien que la verdad es el resultado de la oposición y, paradójicamente, 
también de la contradicción de conceptos. Hegel comienza con una tesis que necesariamente lleva a su antítesis y la cual, analizada por separado, remite nuevamente a la tesis. Por ejemplo, si analizamos la esencia y esa es la tesis, su antítesis sería la no-esencia. Tanto esencia como no-esencia, para Hegel, se conglomeran para, unidas, formar un nuevo concepto. Dicha fusión de conceptos opuestos es la síntesis hegeliana que forma una nueva realidad. Hegel da así un gran valor a la negación que, a su vez, es afirmación, porque es la posesión de los contrarios. Este concepto de Hegel a primera vista puede parecer circular por el juego de opuestos: tesis y antítesis. Sin embargo, no es necesariamente así; puesto que la síntesis es una deducción siempre más compleja que la tesis o la antítesis por sí solas. Es, a fin de cuentas, aprovechar los opuestos para deducir una realidad más completa de ambos conceptos y que, por supuesto, los contenga. Un ejemplo frecuente en la literatura sobre Hegel es el del ser, visto como tesis, que en sí mismo contiene el no-ser, antítesis, y que a su vez remite en sí mismo al ser, puesto que tanto el ser como el no-ser, en abstracto, no se entienden sin aludir a su contrario. La síntesis de Hegel es, para el caso anterior, el devenir. Un concepto nuevo que se asocia con nuestro universo, que está plagado de cambio, y en el cual se da, a su vez, el ser y el no-ser. La filosofía de Hegel aumenta en la medida en que incrementan dichas síntesis puesto que los conceptos iniciales, como el de ser y no ser, en sí mismos dicen muy poco. Todo este juego de conceptos en Hegel culmina en la explicación del ser absoluto, Dios, que es a la larga un concepto enriquecido por todo lo anterior. Dicho de modo veloz, la filosofía de Hegel es un recorrido por el universo para desembocar en la contemplación del ser en su forma más viva y total. No obstante, la pobreza final de ese concepto es casi tan desprovista como la del ser inicial. Viéndolo así, es fácil notar el desencanto inmediato que sintió Russell por Hegel, una vez que lo hubo leído en primera persona.

Aunque Hegel abarca muchos temas y por supuesto las matemáticas son uno de ellos, quiero resaltar lo que entiende él por espiritu subjetivo. En su filosofía, el alma es el principio más básico y no necesariamente es un ente inmortal, es, más bien, un primer motor de existencia. Esta alma está enmarañada en un mundo que va en desarrollo y que adquiere conciencia de sí mismo, 
manifestación última que refleja mayor madurez en la evolución hacia el espíritu. El mayor grado de espíritu, para Hegel, es cuando se alcanza la libertad, concepto que para él dista por mucho de la capacidad de elegir, y es un grado superior de conciencia en el que hay una síntesis del conocimiento propio como sentimiento y la reflexión misma. Este grado, para Hegel, no se alcanza de un modo personal porque el hombre es un ser sociable que necesita de los demás. Por eso, el espíritu subjetivo para Hegel será ese compuesto de la verdad y la conciencia como voluntad inteligible. Este panteísmo de Hegel hace que el universo se asocie a la emanación de un Dios, una idea, un Absoluto que se conoce a sí mismo y que siempre está en desarrollo puesto que el movimiento le es inherente. Existe también para Hegel un espíritu objetivo y dicho espíritu es El Estado. Pese a la importancia que tiene esto último en su filosofía, para nuestra finalidad que sigue siendo el pensamiento de Bertrand Russell hasta encontrar las paradojas de los conjuntos, el espíritu objetivo viene a ser un tema tan periférico como inservible.

McTaggart encarna en viva voz el sentir filosófico y científico de la época, pues fue un hegeliano practicante, dedicado al proselitismo y se convirtió en una de las mayores influencias para que Bertrand Russell se hiciera hegeliano también. La noción filosófica de McTaggart de sustancias unidas por el amor tiene un gran paralelismo con el espiritu subjetivo de Hegel, aunque en él, más que una conciencia propia de un Dios que se forma y conoce a sí mismo, la eternidad ocurre por la donación generosa de almas que formarán dicho espíritu por un amarse. La relación con McTaggart y la adopción por parte de Russell de la filosofía hegeliana, tendrá gran repercusión en la concepción del absoluto matemático de Bertrand que, más tarde, tendrá un desenlace propiamente platónico en el modo de concebir los conjuntos, una vez que se ha desencantado de Hegel y que, por supuesto, es parte esencial en el hallazgo de las paradojas.

La tesis hecha por Bertrand Russell - por cierto perdida - para el grado en Cambridge tenía una estructura dialéctica y dejaba ver su estrecha afinidad con Hegel, a pesar de conocerlo a través de McTaggart. La relación antedicha con Hegel no se percibe solo en lo teórico, sino inclusive en lo más práctico y concreto de su escritura. La tesis coincide con un Russell hegeliano que ha abandonado las ideas kantianas sobre las matemáticas, las ciencias. Ahora no 
le parecen válidas, universales, verdaderas, sino que Russell concebirá en esta época a toda ciencia como algo inherentemente desajustado, incompleto, necesitado de algo más y dichos errores de cada ciencia deben ser suplidos en un todo de prácticas que Russell ve como inferiores pero que, en conjunto, dan una solución final (síntesis) a la veracidad de las cosas. Nótese el parecido: las matemáticas tienen errores en sus principios y dichos principios no pueden solucionarse en la matemática misma (tesis). Por ello, se requiere una ciencia inferior, la física, en la cual esos conceptos matemáticos que no encuentran autosustento pueden ser arreglados (antítesis). A su vez, la misma física tiene errores en sus orígenes que deben ser corregidos por otra ciencia inferior (otro binomio de tesis y antítesis). Todo esto, después de un proceso dialéctico en el que los errores han sido arreglados, dan un conjunto global verdadero de ciencias exactas y prácticas (síntesis), que da un resultado feliz en la veracidad y certeza de nuestros conocimientos científicos y empíricos, pues su cadena de soluciones llega hasta la fisiología.

Es notable cómo el motor de Russell es la búsqueda de la verdad, pero en esta época de su vida, dicha exploración se sortea a través de una filosofía muy distinta a su punto de partida y que, más tarde — así lo verá él一, incluso lo alejó de la ruta deseada. Este modo de proceder, aunque parezca prematuro, delimita muy bien la filosofía que Bertrand Russell legó al mundo y que, al pasar de los años, se ha disuelto en filosofías escépticas. La filosofía de Russell es una filosofía lógica. Pretende reducir la verdad a enunciados atómicos demostrables. Es un reflejo de su necesidad de certezas y, aunque no niega la metafísica, puesto que para Russell es importante una explicación del mundo, en realidad termina agotando la posibilidad de lo trascendental al reducir la verdad a la verdad de las afirmaciones lógicas tipo $a$ y $b$ es verdad, sí y solo sí, tanto $a$ como $b$ lo son de modo independiente. Si quisiéramos entender, antes de proseguir con lo demás, cuáles son los motivos filosóficos de Russell durante su paso por este mundo, podríamos decir sin temor a equivocarnos que son la búsqueda de la verdad, la racionalización del concepto de Dios y la lucha por explicar el mundo solamente a través de las matemáticas y la física, disciplinas que para él tenían más posibilidad de certeza, al menos en la forma.

\section{San Anselmo}


Acabo de mencionar puntos sintéticos que bosquejan la filosofía de Russell y sus anhelos. Uno de esos es la racionalización del concepto de Dios. Esto de racionalización es, a fin de cuentas, un esfuerzo por comprender, cuanto menos, qué se entiende por Dios cuando hablamos de Él. Russell, en su autobiografía, cuenta cómo a los 15 años revisó todas las demostraciones de la existencia de Dios y ninguna le satisfizo. Según él, al principio perdió la fe en las religiones, pero no se hizo necesariamente ateo, pues seguía creyendo en la posibilidad de que ese Dios existiera y de que tuviéramos un alma inmortal pese a no hallar una demostración que le pluguiera. Después de un tiempo, leyó un libro en el que venía la pregunta “¿Quién hizo a Dios?” [Russell 2010,57]. Dicha pregunta bastó para que se declarara ateo. Aquello le parecía la prueba irrefutable de que era ilógica la idea de un Ser Superior. Más tarde, sin embargo, Bertrand tomará por válido el argumento ontológico.

Es usual reservar la palabra demostración para las justificaciones científicas o filosóficas que pueden ser comprobadas, puesto que están organizadas con argumentos válidos, universales y evidentes. Para lo metafísico, por el contrario, es más correcto hablar de pruebas en cuanto son argumentos que alimentan nuestra razón, que son posibles más no probables, pero que, dado que no pertenecen al mundo comprobable bajo el rigor científico, no pueden considerarse propiamente una demostración a la manera de las ciencias exactas. Lo anterior, por supuesto, no garantiza que solo sea cierto lo demostrable. Es importante no perder de vista que el conjunto de cosas que pueden ser probadas por la ciencia es apenas un subconjunto de la realidad y sería muy arriesgado tomar el subconjunto por el todo.

El hecho de que Russell en un momento de su vida creyera en la validez del argumento ontológico, podría parecer a simple vista como una nueva conversión de Bertrand a Dios. Esto no es necesariamente así. Esta conversión de Bertrand era una creencia en un Absoluto como concepto y no tanto un acercamiento a un Dios personal que cambiara el rumbo de su vida. De hecho, para él ese Dios, o Absoluto, tenía mayor relación con la idea matemática de absoluto. Pese a ello y por la importancia que tuvo en su vida y en su concepción del infinito, veo conveniente esbozar en unas cuantas líneas la relevancia del argumento ontológico y de san Anselmo. 
Anselmo nació en el año 1033 y falleció en 1109. Su pensamiento abarca filosofía, gnoseología, lingüística, ascética y teología. Fue obispo en Canterbury, Inglaterra. La corriente de pensamiento de Anselmo tiene parentesco a la de san Agustín en cuanto que la fe y la razón no son contrarias. De hecho, Anselmo tiene un corte claramente realista en su filosofía. Para él hay ideas innatas en el intelecto, pero la razón antecede a los sentidos. Esto es, en realidad, una clasificación del conocimiento natural y del sobrenatural que tendrá su importancia incluso hasta la filosofía de Descartes. En el conocimiento natural la potencia operante es la razón y en el sobrenatural será la fe. Descartes, padre del racionalismo, resaltará más adelante el papel del mundo de la razón y, además, hará su prueba de la existencia de Dios que tendrá grandes similitudes con el argumento ontológico de san Anselmo. Pero no es mi deseo desviar la atención de nuestro obispo de Canterbury y solo procuro con lo anterior, reflejar la importancia que tiene este santo, incluso pasados varios siglos.

Anselmo desea esclarecer la verdad. Por eso, en su libro De veritate hace un estudio de los juicios o enunciados y da un parámetro de evaluación para considerar cuándo un juicio es verdadero o no lo es. Anselmo distingue dos características de la verdad: en primer lugar, la verdad es el Ser, es decir, Dios. En segundo lugar, la verdad serán los juicios lógicos de la razón humana. Entonces Anselmo, con este segundo aspecto de la verdad, procede a dilucidar cuándo un juicio lógico es verdadero. Cada juicio o enunciado es analizado tanto por su forma como por su objeto para calificar su veracidad. Para Anselmo un juicio es verdadero cuando dicho juicio es recto, es decir, se apega al principio de no contradicción. El realismo que mencionaba de Anselmo radica en que no basta con que un juicio sea recto en su forma, pues no se puede quedar solo en un abstracto lógico de buena factura; para que un juicio sea verdadero debe ordenarse a un objeto. La verdad del juicio, entonces, radicará en que sea recto y esté apegado a un objeto real (en el pleno sentido de la palabra), es decir, que también cumpla el principio de identidad.

Como la verdad para Anselmo es en primer lugar Dios, busca razonar la fe, con juicios válidos, de modo que su conocimiento natural sirva de escalafón para el sobrenatural y no se caiga en un fideísmo que es, a fin de cuentas, una fe sin razón y sin razones. Es así como la filosofía de Anselmo desemboca 
en el argumento ontológico que es la búsqueda racional de una realidad metafísica. No pienso exponer el argumento ontológico a detalle, sin embargo, quisiera aclarar que uno de los mayores detractores de Anselmo fue un monje, oriundo de Francia, de nombre Gaunilo. La crítica de Gaunilo parte de la base de que de una idea no se puede deducir, necesariamente, la existencia. Sin embargo, la oposición de Gaunilo no resulta muy pertinente puesto que parte de un juicio contradictorio: una isla con características limitadas que él remplaza por el juicio, no contradictorio, del que parte Anselmo. Recordemos que, para el obispo de Canterbury, la verdad de un juicio depende de que sea recto en lo formal, no contradictorio, y que se apegue a un objeto real. La refutación de Gaunilo es, pues, bastante mala y es el mismo Anselmo quien le da la vuelta haciéndole ver su error.

En realidad, el argumento ontológico no es tan sencillo de refutar, aunque su presentación pueda parecer, a primera vista, inocente. Tan es así que Kurt Gödel, uno de los mejores lógicos que han existido, dio su versión del argumento ontológico usando lógica modal. Para dicha versión moderna (siglo XX) de la prueba de la existencia de Dios, Gödel recurre a los tipos de verdades que hay: necesarias y contingentes. Las necesarias son aquellas que se dan en todos los mundos posibles; las contingentes, aquellas que pueden ser o no ser. Cuando una declaración es verdad en un mundo ajeno al nuestro, pero no es verdadera en otros, dicha verdad es, a lo más, posible. Cuando es verdad en nuestro mundo, pero no lo es en otros, es contingente. Gödel prueba que la afirmación de Dios es verdadera en un mundo y luego, por las características de ese Dios, muestra cómo se vuelve una idea necesaria que es, en resumen, verdadera en todos los mundos posibles.

\section{Leibniz}

Leibniz nació en 1646 y es muy conocido en varias áreas del saber. Hizo grandes aportaciones en matemáticas, en filosofía y en teología. Conoció de humanidades e incluso trabajó como diplomático e hizo aportaciones en el campo del derecho. La mayor parte de su obra, no obstante, permaneció inédita y no hubo noticias de ella hasta su muerte en 1716. Muchos conceptos suyos influyeron en el logicismo de Bertrand Russell. 
Lugar importante ocupan los trabajos de lógica que realizó en el desarrollo de su filosofía. Las conclusiones de Leibniz prepararán el camino de la lógica simbólica que actualmente utilizamos. Este hombre tenía grandes deseos de unión, por ejemplo, deseaba contribuir en la unidad de las iglesias cristianas, y este profundo anhelo de unión, permeaba en sus teorías. Por eso deseaba formar una lógica que mitigara los malentendidos del lenguaje. Leibniz deseaba instaurar un lenguaje universal que pudiera valer para analizar los problemas humanos y, así, eliminar las discusiones carentes de sentido. Deseaba, en el fondo, dotar al mundo de la claridad matemática. Esto nos deja ver un aspecto profundo de su pensamiento y es, a saber, que para Leibniz el mundo está codificado en un lenguaje matemático. Para él, nada hay en el mundo que carezca de razón. Leibniz y Russell comparten un modo similar de ver la realidad. Si recordamos, Bertrand deseaba explicar el mundo bajo un tipo de verdad matemática; Leibniz, unos tres siglos antes, buscaba lo mismo.

Leibniz considera que casi todo pasa en el intelecto por los sentidos, salvo, el intelecto mismo. O sea, que, sin negar el empirismo, da un lugar preeminente a la capacidad innata de la razón. Los avances que hizo en eso tienen mucha relación con ideas que adoptaron posteriormente en psicología sobre el subconsciente. Las verdades de razón eran para él esas ideas preconcebidas que tenían la característica de ser simples y claras. Para este gran hombre el conocimiento racional ocurre gracias a esas verdades de razón que suelen tener dos principios lógicos: ser posibles y ser de razón suficiente. Lo posible de Leibniz se asocia con lo contingente, es decir, lo que en un futuro puede ser, sin embargo, también lo posible de Leibniz se asocia a los conceptos no contradictorios, lo que en Anselmo dijimos que eran los juicios rectos. Lo de razón suficiente tiene que ver con esa concepción matemática de la realidad en la que cada cosa tiene su función y su razón de ser, todo existe por algo y todo es inteligible. La influencia de Leibniz en Russel fue enorme, pues Bertrand traba relación con Louis Couturat, gran experto en Leibniz. Además, pedirán a Russell que sea profesor suplente de McTaggart en unas lecciones sobre Leibniz. Ambas cosas colaborarán para que Bertrand se adentre en la mente de este polifacético hombre y las ideas de una lógica capaz de eliminar cualquier discordia o malentendido harán mella profunda en su pensamiento. 
El logicismo, postura que pone a las matemáticas en un nivel inferior a la lógica, incluso como una rama de esta, será una de las aportaciones más grandes de Bertrand Russell para el mundo. Pues bien, este logicismo tiene mucho de la lógica de Leibniz y sin él, seguro esta noción de Russell no se hubiera inmortalizado al pasar el tiempo.

Lo dicho hasta ahora de filosofía no agota las influencias que tuvo Russell en su pensamiento, esto es tan solo un marco para entender parte del entramado interior que lo condujo a ser él, y no otro, quien descubriera las tres paradojas de la teoría de conjuntos: la de las clases infinitas, la de los conjuntos bien-ordenados, la del conjunto de cardinales finitos. Otra sección importante para la comprensión global de la cuestión compete a los conceptos matemáticos que, de forma similar a los descritos aquí, fueron modificándose con cierta plasticidad y lo aproximaron a modos de entender los conjuntos que le facilitarían entender el grave problema que subyacía en la teoría de conjuntos. El descubrimiento de las paradojas por parte de Russell no fue algo de un instante; su intelecto se fue poblando de ideas, fue descartando unas, adueñándose de otras, hasta que estuvo preparado para divisar que algo complicado se fraguaba en la teoría de conjuntos de Cantor, tal y como estaba. Lamentablemente explicar esto al detalle, como me gustaría, haría muy extenso este trabajo y se escaparía del ámbito filosófico al que deseo ceñirme para este artículo. Simplemente daré unas brevísimas pinceladas que mostrarán, con poca exactitud, el recorrido de Russell hasta su gran aportación en las matemáticas.

Russell, desde temprana edad, manifiesta un fuerte deseo de probar los postulados de Euclides. Este será el motor de sus anhelos intelectuales durante un largo periodo. Sin embargo; la meta propuesta por él se torna más ambiciosa con los años: no le bastan los postulados, busca fundamentar hasta lo más remoto de las matemáticas. No es fortuito que el título del libro que escribe con Whitehead sea Principia Mathematica. Su modo de concebir los números y el infinito no le permiten, durante su vida universitaria y sus primeros años de graduado, dialogar con la teoría de conjuntos de Cantor en la cual tienen lugar las contradicciones o paradojas. No obstante, el abandono del hegelianismo y la aceptación del argumento ontológico, entre muchas más cosas, abren una brecha que favorece el diálogo con los transfinitos de Cantor. 
Russell tiene una manera peculiar de concebir los conjuntos y no ceja un ápice en desprenderse de la realidad; por ello, sus ideas y las de Cantor son, al principio, tan ajenas. El paso del odio al amor es gradual y Russell adopta, con lentitud, algunos conceptos de Cantor. Para Russell, Cantor es un enemigo que funge como aliado, pues es en el desencuentro donde más se robustece el ingenio de Bertrand. Su tardía apertura a entender el infinito actual lo prepara para comprender a Cantor y le permite tomar cierta distancia en su singular forma de ver los conjuntos. Este Russell, más maduro, con mayor apertura al abstracto, es el que intuye que los conjuntos no se pueden definir a la ligera, pues generan calamidades que en matemáticas desagradan más que en otros lares, por ejemplo, conjuntos que se contienen a sí mismos justamente cuando no se contienen, o conjuntos que no se contienen precisamente cuando se contienen. Pero este asunto de cómo llegó Russell exactamente a ellas, lo dejaremos para otra ocasión.

\section{Bibliografía}

Amor, J. A. (2011). Teoría de conjuntos para estudiantes de ciencias. México: UNAM. Las prensas de ciencias.

Doxiadis, Papadimitriou. (2014). Logicómix. Una búsqueda épica de la verdad. Barcelona: Publicaciones y Ediciones Salamandra, S. A.

Euclides. (2000). Elementos. Libros I-IV. Barcelona: Biblioteca Básica Gredos.

Garciadiego, A. R. (1992). Bertrand Russell y los origenes de las "paradojas" de la teoría de conjuntos. Madrid: Alianza Editorial.

Russell, B. (2010). Autobiografia. Barcelona: Edhasa.

Xirau, R. (2011). Introducción a la historia de la filosofía. México: UNAM.

Felipe Maya fmayarestrepo@gmail.com 